\title{
Young e-cyclists in Israeli cities: a characterization of typical behaviours and risk factors based on field observations
}

\author{
Victoria Gitelman $^{a}$, Anna Korchatov ${ }^{a}$, Roby Carmel $^{a}$, Wafa Elias ${ }^{b}$ \\ ${ }^{a}$ Transportation Research Institute, Technion City, Haifa, Israel 32000 \\ ${ }^{b}$ Shamoon College of Engineering, Jabotinsky str. 84, Ashdod, Israel 77245

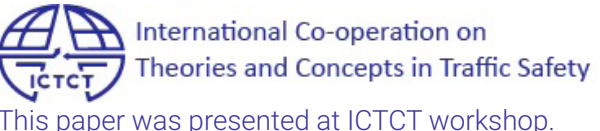 \\ This paper was presented at ICTCT workshop.
}

ABSTRACT: Electric power-assisted bicycles (e-bicycles) provide a convenient form of mobility in urban areas, being an attractive alternative to private cars, usual cycling and walking. However, there is a growing concern of their associated injuries, resulting from the increasing exposure and apparently higher speeds. Unlike other countries, in Israel, a growing use of e-bicycles by youngsters (below 18) is observed, in many towns, accompanied by a substantial increase in the number of related injuries. In this study, an observational survey of young e-cyclists was undertaken in Israeli towns aiming to characterize their behaviours at typical urban settings and then to consider measures needed for their safe integration in the urban space. The observational survey was focused on teen e-cyclists' behaviours during their trips to and from school and during leisure hours. The data were collected by means of dynamic video-recording, at five types of urban settings: signalized and un-signalized intersections; roundabouts; street sections with and without bicycle-paths. The survey covered 225 locations in 15 cities, including 150 sites near highschools and 75 in city centers. In total, over 2000 video-films were collected and their contents were coded for statistical analyses. The results showed that at all types of sites, most teenager e-cyclists were males, older than 16 and not wearing a helmet, despite the traffic law demands. High shares of them rode on sidewalks and crossed at crosswalks, violating the law that prohibits using pedestrian facilities for riding. At signalized intersections, substantial shares crossed on red, both on the roadway and on crosswalks, thus violating the traffic law and increasing accident risk. At various urban settings, young e-cyclists demonstrated a wide range of risky manoeuvres. They move faster than pedestrians and endanger them on sidewalks, but also disturb vehicle traffic and endanger themselves while riding on the road. A wider application of bicycle infrastructure, with better separation between the sidewalks, roadways and bicycle paths, would lead to a safer integration of e-bicycles in Israeli cities. Additionally, road safety education and training of teen e-cyclists supported by stronger enforcement of traffic regulations are required.

KEYWORDS: Urban settings; e-bicycles; youngsters; behaviours

\section{INTRODUCTION}

Recently, a rapid increase is observed in the use of electric power-assisted bicycles (known as e-bicycles, e-bikes or pedelec) throughout the world and in Israel. According to the Free Import Order (2011) in Israel, electric bicycles are defined as bicycles with two-wheels composed one after the other and fitted with an electric engine. They have three groups of components: bike parts, the engine and the battery. In general, there are models in which the engine operates with a switch or throttle and provides power assistance without any pedal action (powered bicycles) and models in which the power assistance is only provided when the rider is pedaling (power-assisted bicycles or pedelec) (Rose, 2012). The definitions and regulations concerning electric bicycles typically involve restrictions on the maximum power of the engine and a maximum speed the bicycle can reach, however, they differ among the countries (Rose, 2012; MacArthur and Kobel, 2014). 
In the European Union, as electric bicycles are defined only such which satisfy the following conditions: the engine power is limited to 250 watts, speed - up to $25 \mathrm{kph}$, and obligatory pedaling (EN 15194, 2009). Bicycles that meet these requirements do not need a driving license, insurance and vehicle license. They can move on bicycle lanes and roads, like a regular bicycle. By contrast, vehicles that exceed these requirements belong to a category of scooters/motorcycles, with an obligation of licensing and insurance. A similar approach was adopted in Israel. According to Traffic regulations (2016), an electric bicycle (e-bicycle) is defined as a bicycle having an electric motor and satisfying the following conditions: (1) The engine's maximum power does not exceed 250 watts; (2) The electric motor is powered by bicycle pedals; (3) The engine power decreases with speed increasing and stops the operation when bicycle speed exceeds $25 \mathrm{~km} / \mathrm{h}$. To ride such e-bicycles there is no need for a vehicle license or a driving license. The permissions and prohibitions for such e-bicycles are identical to those of conventional bicycles. Figure 1 presents a common type of e-bicycles in Israel, which is characterized by relatively small wheels of 20 inch in size. The battery and engine are the two main components enabling to visually distinguish between an e-bicycle and a conventional bicycle.

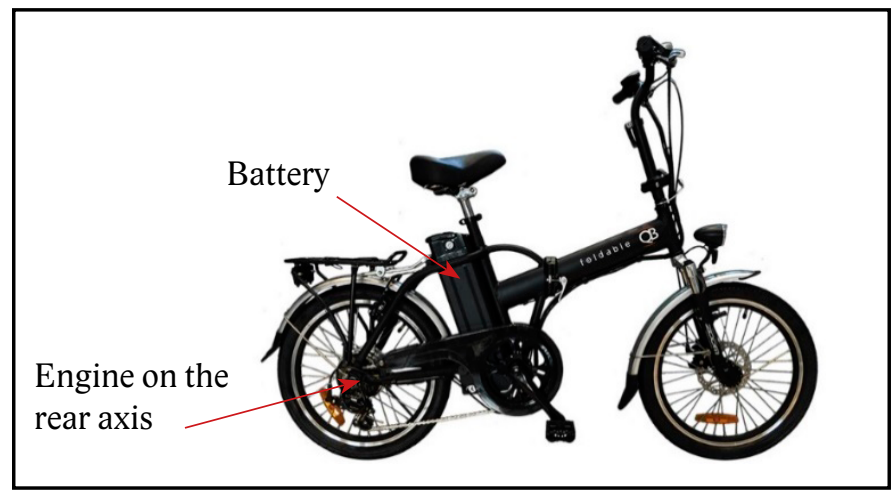

Figure 1. A typical e-bicycle in Israel. Source: http://qbicycle.co.il/product.

\section{THE TRENDS IN USING ELECTRIC BICYCLES AND THEIR IMPLICATIONS ON URBAN MOBIL- ITY AND SAFETY}

According to global estimates, the electric bicycle sales in the world were over 40 million units in 2015, of which 36.8 million (91.9\%) were sold in China and over 2.3 million (5.8\%) in Europe (Fishman and Cherry, 2016). The number of electric bicycles is rap- idly rising in Europe: between years 2011-2015 the total amount of sales increased by $88 \%$ (Fishman and Cherry, 2016). In countries, such as Austria and Germany, the sales of e-bicycles have doubled from 2010 to 2012, while in Switzerland the sales increased by $50 \%$ and in Italy and France by $20 \%$ (Dozza et al., 2013). Germany and the Netherlands are the leading e-bicycle markets, accounting for $44 \%$ and $21 \%$, respectively, of the total European Union sales (Fishman and Cherry, 2016).

Fishman and Cherry (2016) state that electric bicycles represent the largest and the most rapid uptake of alternatively fueled vehicles in the history of motorization. MacArthur et al. (2014) estimated that the worldwide sales of e-bikes are expected to be 47.6 million by 2018. Hurst and Gartner (2013) presented a forecast scenario of the e-bike growth by world regions, and suggested that the annual e-bike sales in the world (excluding China) will approach 4 million in 2020 and may be even higher according to an aggressive forecast.

The estimates reported in Israel - a country with a population of 8.5 million inhabitants and no long tradition of cycling, indicate a rapid growth in electric bicycles sales: in 2013, 32,851 units were imported to Israel, in 2014 - additional 72,602 units and year 2015 ended with an addition of 100,000 units (Morgenstein, 2016). This means that over 200,000 electric bicycles were sold in Israel in a period of three years.

The electric assistance to the rider reduces the physical efforts required for riding an e-bicycle. Therefore, e-bikes are associated with a potential to expand the role of cycling in urban transport (Rose, 2012). E-bicycles may provide a convenient form of mobility in urban areas, being an attractive alternative to private cars, usual cycling and walking. Studies show that the durations and distances of travels performed by electric bicycle riders increase compared to travels on conventional bicycles and that e-bikes often replace private car travels for daily purposes (Cherry and Cervero, 2007; Jonhson and Rose, 2013; Fyhri and Fearnley, 2015). In addition, electric bicycles are useful for people who are not able to ride conventional bicycles due to physical limitations or ageing (MacArthur et al., 2014; Boele-Vos et al., 2017).

However, there is a growing concern of e-cyclists' injury, resulting from the increasing exposure and apparently higher speeds. Empirical studies showed that electric bicycle riders usually rode faster than conventional bicycle riders, yet, the speed differences are not big. For example, in the naturalistic cycling 
studies conducted in Tennessee, USA, and Germany, the mean speeds of e-bicycles were higher by 2-3 km/h compared to regular bicycles (Langford et al., 2015; Schleinitz et al., 2017). Research findings from Sweden and Germany indicate that the chance of e-bicycle riders to be involved in conflicts with other road users is higher compared to conventional bicyclists and that the risk to be involved in a conflict increases at intersections, in the proximity of crosswalks and with an increase in riding speeds (Dozza et al., 2016; Petzoldt et al., 2017).

Studies from the USA and Europe demonstrated more safety-aware behaviours of electric bicycle users, with regard to helmet use, compliance with traffic signs and more careful riding on bicycle-shared paths, or no considerable differences compared to conventional bicycle riders (Scaramuzza et al., 2015; Langford et al., 2015; MacArthur et al., 2014). At the same time, studies from China, found high rates of law violating and dangerous behaviours among e-bike riders, such as passing through red lights and carrying another person on the bike (Du et al., 2013; Yang et al., 2015). (It should be noted that e-bike regulations are different in China compared to Europe, with no limit imposed on engine power and no obligation on pedaling, see Rose, 2012; as a result, more unruly behaviours of e-bike riders can be expected.)

The evaluation studies of road traffic injury reported that, in China, the risk of e-bike riders to be killed in a road accident or to suffer severe injuries is higher compared to conventional bicycle riders (Cherry and Cervero, 2007; Hu et al., 2014). In the Netherlands, Schepers et al. (2014) found that after controlling for the age, the gender and the amount of bicycle use, e-bicycle riders are more likely to be involved in an accident that requires medical treatment, compared to conventional bicyclists.

\section{THE SITUATION IN ISRAEL AND THE STUDY'S TOPIC}

Studies conducted in other countries, e.g. in the USA, Australia, Europe and China, found that e-bike users are mainly men, aged 30 and above, with higher income and education levels compared to users of conventional bicycles (Cherry and Cervero, 2007; Johnson and Rose, 2013; Popovich et al., 2014; Scaramuzza et al., 2015). In Israel, unlike other countries, there is a high share of youngsters riding on electric bicycles - teenagers below the age of 18 , some of them younger than 16 years. Young e-bicycle riders can be met on sidewalks, roads, bicycle routes and junctions of towns, especially in the hours of going to and from school, where some of them ride at seemingly high speeds.

According to Traffic regulations (2016) in Israel, only people aged 16 and above are allowed to ride electric bicycles. Previously, before May 2016, a person over the age of 14 was permitted to ride an e-bicycle but on bicycle lanes only, whereas a person over the age of 16 was permitted to ride it also on roads. Today, e-bicycles are allowed to ride on bicycle facilities and on roads, and are not allowed to ride on sidewalks, crosswalks or other pedestrian places. In urban areas, wearing a helmet is mandatory for cyclists under the age of 18 . A rider can carry another person on the bicycle only if it is fitted for carrying, i.e. has more than one seat.

There are various media reports in Israel stating that on urban streets, mainly in the center the country, young e-bicycle users ride recklessly, ignore the traffic regulations, some of them ride at high speeds on sidewalks and disturb pedestrians' movement. This phenomenon is widely discussed by various authorities in Israel, whilst its actual characteristics are unknown.

The data from the national trauma registry in Israel (Gertner Institute, 2014; 2015), indicated a drastic increase, over the last years, in the amount of injuries associated with electric bicycles (and scooters') accidents. They showed that, in 2013, there was an increase of $360 \%$ in the number of injuries hospitalized as a result of such accidents compared to 2012, where the number was ten times higher compared to 2010 and 46 times higher compared to 2009. In the first quarter of 2015 compared to the same quarter of 2014, the number of patients hospitalized following such accidents indicated an increase of 3.4 times. The age distribution of all e-bicycles' (and e-scooters') injuries in the years 2008-2014, demonstrated that about half of all injuries were to children up to 17 years old.

Being aware of the growing phenomenon of using e-bicycles by youngsters in Israeli towns, with their seemingly dangerous behaviours and already negative implications of road traffic injury, an observational survey of teen e-cyclists was undertaken in this study. The survey aimed to explore the young e-cyclist behaviours at various urban settings, to characterize their typical behaviours and interactions with other road users and then to consider measures 
needed for their safer integration in the urban space. Such an observational survey was particularly relevant because the findings on e-cyclists' behaviours in the international literature are not extensive, and mostly refer to adults (see Sec. 2 above).

\section{METHODOLOGY}

\subsection{Site selection}

The observational survey was focused on young e-cyclists' behaviours during their trips to and from school and in leisure hours. Hence, the observational sites were selected in the surroundings of high-schools and in the vicinity of city centers. The experience of previous Israeli studies indicated that large- and medium-sized towns, situated along the seaside and in the center of the country, with flat landscape and medium-high socio-economic levels, are associated with an increasing use of e-bicycles by youngsters. In such towns, larger numbers of young e-cyclists can be met. Following these criteria, a preliminary list of towns - candidates for the survey, was composed moving along the seaside from the North to the Center of the country - the Tel-Aviv metropolitan area and its surroundings.

The main purpose of the survey was to observe young e-cyclists during their rides from home to school in the morning and on their way back in the afternoon. In order to select areas near high-schools with potentially higher amount of bicycles, the sites of high-schools were visited in weekday mornings. A preliminary list of schools with large amounts of pupils - more than 800, was prepared for each town (using an internet site that publishes information about all highschools in Israel), and maps with school surroundings were drafted, for a field survey. While visiting the school site in the morning, the amount of e-bicycles in the parking place was checked. If a substantial amount - 20 or more electric bicycles parked near the gates, was observed, the study team applied to the school guard asking for information on the starting and ending times of the school lessons, when the majority of e-cyclists come to and leave the school, and the directions of their travels. Then, the street grid leading to the school gates was examined using the maps and visual checks of sites - traffic arrangements in the school surroundings, were conducted. Five types of urban settings were defined for collecting e-cyclists' behaviours in the study, which are: signalized and unsignalized intersections, roundabouts, and street sec- tions with and without bicycle-paths. Thus, near each high-school included in the study, a set of sites from the pre-defined five types was selected for observations of young e-cyclists' behaviours on their way to or from the school, with observation hours required.

In a similar way, the observation sites for afternoon leisure activities of young e-cyclists were selected. Such sites were identified during preliminary field surveys in the vicinity of commercial centers and city centers in the pre-selected towns, on weekdays, between the hours 14-18. The sites were selected among five types of urban settings that were introduced above; a site was included in the survey if a certain amount of young e-cyclists was observed during a preliminary tour (at least 3 riders in ten minutes).

In total, the observational survey covered 225 locations in 15 cities, including 150 sites near schools and 75 in city centers as presented in Table 1 . The sample comprised 31 areas near high-schools and 18 areas in city centers.

\subsection{Data collection}

The data were collected by means of a video-recording of young e-bicycle riders, in the pre-defined hours. At each site, an observer with a camera (usually, a smart-phone) was waiting and for each appearance of a young e-cyclist, a video-film was recorded. When possible, the film recorded how the e-cyclist approached the site, crossed the site and continued riding after leaving the site. The position of an observer at the site was dynamic and might change depending on the place and the direction of the e-cyclist's appearance.

The observational hours were typically defined as follows: for the near-school sites - between 7:30-9:00 in the morning, between 12:30-14:30 in the afternoon (for each area, more detailed hours were specified depending on the school) and for the sites in city centers - between 15-19. At each site, the observer was required to stay for half an hour and to record all young e-cyclists' appearances. If ten e-cyclists were video-recorded in a shorter time period, the observer could move to another site. The presence of an observer apparently did not impact the e-cyclist behaviours due to his dynamic position and relatively short presence at each site and usually quick movement of e-cyclists through the site (most films were of 10-20 seconds in length).

The observational survey was conducted between mid May - mid June of 2016 (before the end of the 
school year). In total, over 2,000 video-films were collected, of which two thirds were from the near schools' areas and a third from city centers. Figure 2 provides examples of young e-cyclists observed at urban junctions.

\subsection{Data analyses}

The films' contents were coded, to produce data in a numerical format and enable statistical analyses. For the coding, common forms were developed, for each type of site, aiming to reflect e-cyclist character-

Table 1. The amount of sites selected for the observational survey of young e-cyclists.

\begin{tabular}{|c|c|c|}
\hline Towns & No of school areas & No of observational sites \\
\hline Krayot*: Kiryat Yam, Kiryat Motzkin, Kiryat Bialik & 3 & 11 \\
\hline Nahariya & 1 & 6 \\
\hline Haifa & 1 & 4 \\
\hline Hadera & 2 & 10 \\
\hline Netanya & 4 & 24 \\
\hline Tel-Aviv - North & 3 & 15 \\
\hline Tel-Aviv - Center & 2 & 12 \\
\hline Ramat Gan, Givatayim & 2 & 10 \\
\hline Herzliya & 4 & 15 \\
\hline Ra'anana & 3 & 20 \\
\hline Kfar Saba & 4 & 12 \\
\hline Bat Yam, Holon & 2 & 11 \\
\hline In total: 15 towns & 31 areas & 150 sites \\
\hline \multicolumn{3}{|l|}{ b - Sites in city centers } \\
\hline Towns & No of areas & No of sites \\
\hline Krayot*: Kiryat Yam, Kiryat Bialik & 2 & 7 \\
\hline Nahariya & 2 & 7 \\
\hline Netanya & 3 & 17 \\
\hline Hadera & 2 & 8 \\
\hline Tel-Aviv - North & 3 & 12 \\
\hline Tel-Aviv - Center & 3 & 12 \\
\hline Ramat Gan, Givatayim & 3 & 12 \\
\hline In total: 8 towns & 18 areas & 75 sites \\
\hline
\end{tabular}

* A cluster of small cities in the Haifa Bay area

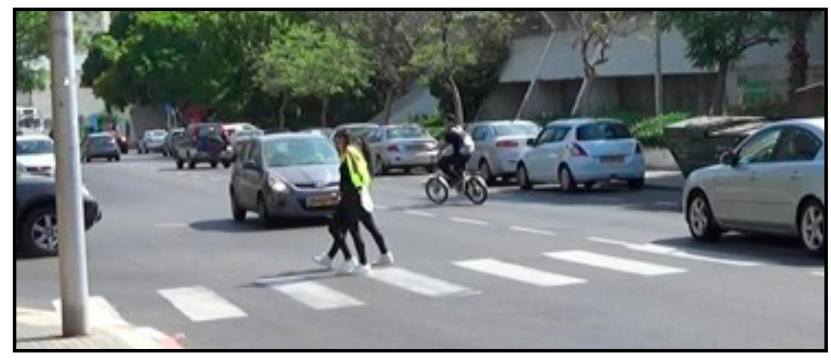

a

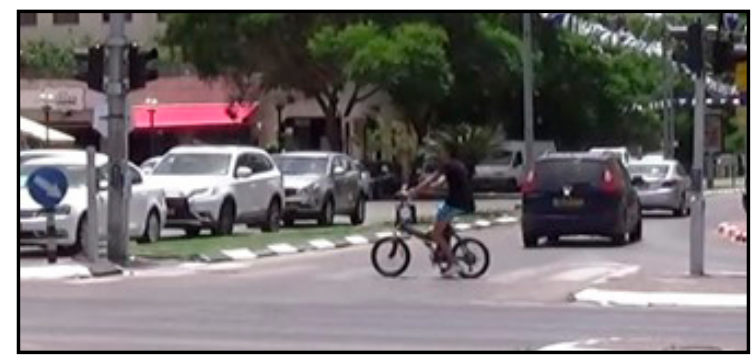

b

Figure 2. Examples of young e-cyclists observed on urban settings in Israel: (a) at an un-signalized junction, (b) at a signalized junction. 
istics and behaviours, riding conditions, interactions with other road users, traffic law violations and conflicts observed. To account for possible differences among the sites of each type, road and traffic conditions of each site were also coded, e.g. the number of legs of an intersection, the layout (single- versus dual-carriageway) of a street section, the level of traffic volume during e-cyclist appearance, etc. For junctions, the data were coded separately for each step of e-cyclist movement: while travelling on a street section before the junction, while crossing a junction and while travelling on a street section after the junction. A conflict was defined as an abrupt change in the speed and/or the direction of travel, by the rider or other road user in order to avoid a collision, in line with previous research (Ewing and Dumbaugh, 2009; Gitelman et al., 2017). A further analysis of conflicts was applied using a method based on the Dutch traffic conflict technique (Van der Horst et al., 2014).

Using the coded data, first, the profiles of young e-cyclists across various types of urban traffic settings were examined, in terms of their age groups, gender, wearing bicycle helmets and carrying a passenger. Concerning the age groups, originally, in line with the law, three categories were defined: teenagers below 14, ages 14-16 and teens older than 16. Following the law change in May 2016 that restricted the use of e-bicycles to the age of 16 and above, in this study's analyses only two categories were considered: teenagers older than 16 versus younger teens. The age groups of riders were recognized visually. To be consistent in the recognition, a set of typical examples was developed for the use by the study team and a calibration training was conducted to recognize the age. In the case of doubt with regard to a specific film, the age group of a rider was defined in the discussion of two team members.

Second, summaries of e-cyclist behaviours were produced for various types of settings, focusing on the selection of place of riding (sidewalk versus roadway); traffic conditions - the extent of vehicle or pedestrian presence near the rider; keeping the place of riding by e-cyclist; moving slower or faster than other road users; obeying traffic rules, e.g.

Table 2. Characteristics of young e-cyclists observed on various urban settings.

\begin{tabular}{|c|c|c|c|c|c|c|}
\hline Type of site & & $\begin{array}{l}\text { No of riders } \\
\text { observed }\end{array}$ & $\begin{array}{l}\text { Teenagers older than } \\
16 \text { vs younger teens }\end{array}$ & $\begin{array}{l}\text { Males vs } \\
\text { females }\end{array}$ & $\begin{array}{l}\text { Wearing a helmet: } \\
\text { no vs yes }\end{array}$ & $\begin{array}{l}\text { Carrying a passenger: } \\
\text { yes vs no }\end{array}$ \\
\hline \multirow[t]{2}{*}{ Road sections near schools } & $\mathrm{N}$ & 69 & 54 & 52 & 58 & 7 \\
\hline & $\%$ & 100 & $78.3 \%$ & $75.4 \%$ & $84.1 \%$ & $10.1 \%$ \\
\hline \multirow[t]{2}{*}{ Road sections - city centers } & $\mathrm{N}$ & 43 & 29 & 41 & 43 & 3 \\
\hline & $\%$ & 100 & $67.4 \%$ & $95.3 \%$ & $100.0 \%$ & $7.0 \%$ \\
\hline \multirow{2}{*}{$\begin{array}{l}\text { Road sections with bicycle } \\
\text { paths near schools }\end{array}$} & $\mathrm{N}$ & 63 & 52 & 48 & 54 & 6 \\
\hline & $\%$ & 100 & $82.5 \%$ & $76.2 \%$ & $85.7 \%$ & $9.5 \%$ \\
\hline \multirow{2}{*}{$\begin{array}{l}\text { Road sections with bicycle } \\
\text { paths - city centers }\end{array}$} & $\mathrm{N}$ & 46 & 46 & 34 & 41 & 1 \\
\hline & $\%$ & 100 & $100.0 \%$ & $73.9 \%$ & $89.1 \%$ & $2.2 \%$ \\
\hline \multirow{2}{*}{$\begin{array}{l}\text { Un-signalized junctions } \\
\text { near schools }\end{array}$} & $\mathrm{N}$ & 572 & 537 & 501 & 535 & 71 \\
\hline & $\%$ & 100 & $93.9 \%$ & $87.6 \%$ & $93.5 \%$ & $12.4 \%$ \\
\hline \multirow{2}{*}{$\begin{array}{l}\text { Un-signalized junctions - } \\
\text { city centers }\end{array}$} & $\mathrm{N}$ & 66 & 65 & 60 & 64 & 5 \\
\hline & $\%$ & 100 & $98.5 \%$ & $90.9 \%$ & $97.0 \%$ & $7.6 \%$ \\
\hline \multirow[t]{2}{*}{ Roundabouts near schools } & $\mathrm{N}$ & 185 & 122 & 159 & 166 & 37 \\
\hline & $\%$ & 100 & $65.9 \%$ & $85.9 \%$ & $89.7 \%$ & $20.0 \%$ \\
\hline \multirow[t]{2}{*}{ Roundabouts - city centers } & $\mathrm{N}$ & 116 & 50 & 106 & 113 & 10 \\
\hline & $\%$ & 100 & $43.1 \%$ & $91.4 \%$ & $97.4 \%$ & $8.6 \%$ \\
\hline \multirow{2}{*}{$\begin{array}{l}\text { Signalized junctions near } \\
\text { schools }\end{array}$} & $\mathrm{N}$ & 506 & 499 & 402 & 458 & 64 \\
\hline & $\%$ & 100 & $98.6 \%$ & $79.4 \%$ & $90.5 \%$ & $12.6 \%$ \\
\hline \multirow{2}{*}{$\begin{array}{l}\text { Signalized junctions - city } \\
\text { centers }\end{array}$} & $\mathrm{N}$ & 303 & 302 & 258 & 288 & 44 \\
\hline & $\%$ & 100 & $99.7 \%$ & $85.1 \%$ & $95.0 \%$ & $14.5 \%$ \\
\hline Chi-square & & & 493.82 & 36.64 & 30.00 & 20.68 \\
\hline p-value & & & $<0.0001$ & 0.0003 & 0.0004 & 0.0127 \\
\hline
\end{tabular}


the red lights at signalized junctions, etc. Third, the impacts of various road and traffic conditions on e-cyclist behaviours were examined using statistical tools, such as a Pearson Chi-square test, for a univariable analysis, or fitting a binary logistic regression model, for a multi-variable analysis (Fleiss et al, 2004). The statistical analyses were applied aiming to reveal leading behaviour patterns of young e-bicycle riders, their interactions with other road users and common risky behaviours, at typical urban infrastructure settings.

\section{RESULTS AND DISCUSSION}

\subsection{Profiles of young e-cyclists}

Table 2 and Figure 3, a-b, illustrate the profiles of young e-cyclists across various types of urban traffic settings, both near high-schools' areas and in city centers.

At most settings, the majority of riders were over 16 years old, yet, a significant difference was found between the location types $(\mathrm{p}<0.0001)$. The share of younger e-cyclists, below 16, was very low at all

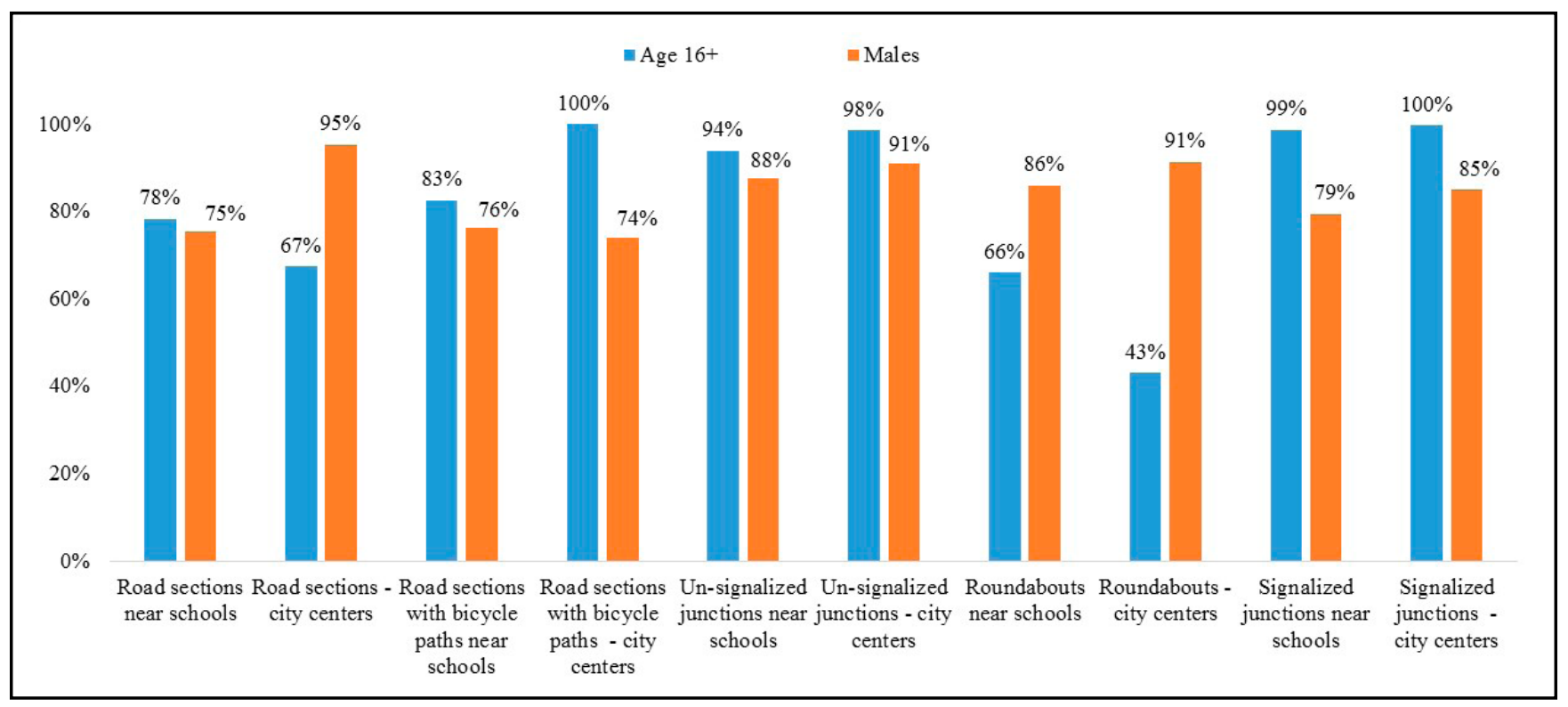

a

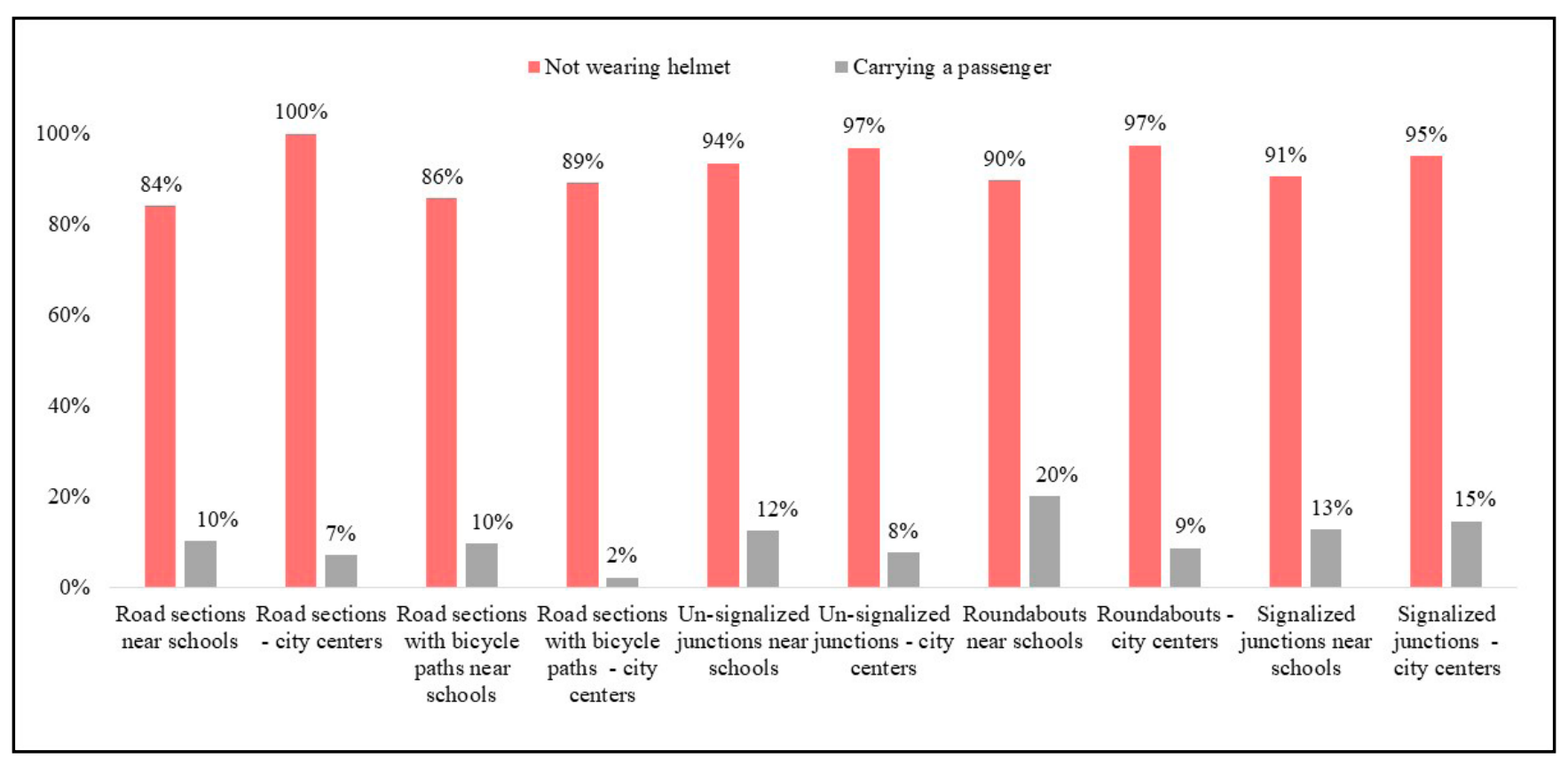


junctions and on street sections with bicycle paths in city centers (from zero to 6\%), was higher on street sections without bicycle paths and on sections with bicycle paths near schools (between 17\% and 33\%) and was highest on roundabouts (34\% near schools and $57 \%$ in city centers). Overall, $11 \%$ of e-cyclists observed were below 16 . The majority of riders $-84 \%$, on average, were boys, but with significant differences between the location types $(p<0.001)$. At such locations as un-signalized junctions and roundabouts, both in city centers and near schools, and road sections and signalized intersections in city centers, the share of girls was lower, in the range of $5 \%-15 \%$. On the other hand, higher shares of girls among the riders (21\%-26\%) were observed on street sections and at signalized intersections near schools, and on all street sections with bicycle paths.

The majority of riders did not wear a bicycle helmet at all types of sites (although, differences between the location types were found, $\mathrm{p}<0.001)$. Overall, only $8 \%$ of riders wore a helmet; the rate was higher (10\% or more), on street sections near schools, on street sections with bicycle paths, at roundabouts and at signalized junctions near schools. The shares of riders that carried a passenger differed between various types of settings $(p<0.05)$, whereas a higher frequency of such behaviour (10\% and over) was observed near schools - on street sections, signalized and un-signalized junctions and roundabouts, and also at signalized junctions in city centers. Overall, $13 \%$ of e-cyclists carried a passenger.

As became clear, the findings pointed to the violation of traffic law on the obligatory use of bicycle helmets, by the majority of young e-cyclists, and to additional violations of the regulations on age restriction for the use of e-bicycles and on carrying a passenger by a smaller share of riders (slightly over $10 \%$, on average, but with higher shares at some location types).

Table 2 shows that the largest samples of young e-cyclists were observed at un-signalized junctions near schools and at signalized junctions near schools and in city centers. A detailed consideration of e-cyclist behaviours at various urban settings, that is presented further in this paper, will focus on these location types.

\subsection{E-cyclist behaviours at un-signalized junctions, near schools}

While an e-cyclist rides through an un-signalized junction, three steps of movement can be recognized: travelling on a street section before the junction (A), crossing a junction (B) and travelling on a street section after the junction (C). For these steps of e-cyclist travels through un-signalized junctions, near schools, the samples of 332, 394 and 415 riders were observed. The summary statistics (Figure 4, Table 3) revealed that:

- At un-signalized junctions, young e-cyclists, in general, prefer to travel on the roadway and not on sidewalks (55\% while crossing a junction, $65 \%$ after the junction). However, a substantial share of them (31\%-52\%, at various steps) used pedestrian facilities, which is prohibited by the traffic law.

- When e-cyclists rode on the roadway, most of them (78\%-79\%) used the right lane, as prescribed by the law. However, over $20 \%$ of riders used other places to ride (the middle of the road, an opposite lane), thus violating the traffic law. Vehicle traffic was present in less than $40 \%$ of cases observed, however, e-cyclists moved slower than vehicles in $47 \%-62 \%$ of such cases and thus, may interrupt the traffic flow. Moreover, some $20 \%$ of riders changed their position on the roadway during the riding, which might increase the extent of disturbance to other vehicles.

- When they rode on the sidewalks before and after the junctions, in more than half of the cases pedestrians were present on the streets and, hence, the riders might disturb the pedestrians. In addition, between $6 \%$ to $10 \%$ of riders tend to change their place of travel between sidewalk to roadway and vice versa, thus, increasing the disturbance to other road users.

- When the e-cyclists crossed a junction on the roadway, half of them did not slow down before the junction and $13 \%$ violated the sequence of turns (when other vehicles were present).

- When they crossed a junction on pedestrian crosswalks, $16 \%$ of them did not slow down before the crossing, $89 \%$ moved faster than crossing pedestrians (when pedestrians were present) and $34 \%$ continued the riding on the roadway. In addition, almost all e-cyclists crossed by riding on the crosswalk, which is prohibited by the traffic law. 
Table 3. Young e-cyclists' behaviours and travel conditions at un-signalized junctions, near schools.

a - Travel on a street section before the junction (step A)

\begin{tabular}{llll}
\hline Place of riding & Sample of e-cyclists observed & Rider's behaviours and travel conditions & Frequency \\
\hline Both & 332 & Undivided two-lane road (vs a divided road) & $90 \%$ \\
On sidewalk & 174 & Passed near pedestrians & $53 \%$ \\
& & Went down to the road while riding & $10 \%$ \\
On roadway & \multirow{2}{*}{158} & Rode on the right lane (vs others) & $78 \%$ \\
& & Vehicle traffic was present on the road & $38 \%$ \\
& & Moved slower than vehicles* & $47 \%$ \\
& & Changed the position on the roadway & $20 \%$ \\
& & Went up to the sidewalk while riding & $10 \%$ \\
\hline
\end{tabular}

\section{b - Crossing a junction (step B)}

\begin{tabular}{llll}
\hline Place of riding & Sample of e-cyclists observed & Rider's behaviours and travel conditions & Frequency \\
\hline All & 394 & 3-legged junction (vs 4-legged) & $72 \%$ \\
& \multirow{3}{*}{ On roadway } & Going straight (vs turning) & $52 \%$ \\
& & Vehicle traffic was present at the junction & $27 \%$ \\
& & Did not slow down before the junction & $51 \%$ \\
& & Violated the sequence of turns* & $13 \%$ \\
On pedestrian crosswalks & \multirow{2}{*}{115} & Went up to the sidewalk while riding & $4 \%$ \\
& & Pedestrians were present & $16 \%$ \\
& & Did not slow down before the crosswalk & $16 \%$ \\
& & Crossed by riding & $99 \%$ \\
On sidewalk & Changed the place to roadway & $34 \%$ \\
& & Moved faster than pedestrians** & $89 \%$ \\
& \multirow{2}{*}{62} & Passed near pedestrians & $29 \%$ \\
\hline
\end{tabular}

c - Travel on a street section after the junction (step C)

\begin{tabular}{llll}
\hline Place of riding & Sample of e-cyclists observed & Rider's behaviours and travel conditions & Frequency \\
\hline Both & 415 & Undivided two-lane road (vs a divided road) & $72 \%$ \\
On sidewalk & 130 & Passed near pedestrians & $52 \%$ \\
& & Went down to the road while riding & $6 \%$ \\
On roadway & 285 & Rode on the right lane (vs others) & $79 \%$ \\
& & Vehicle traffic was present on the road & $36 \%$ \\
& Moved slower than vehicles* & $62 \%$ \\
& & Changed the position on the roadway & $23 \%$ \\
& & Went up to the sidewalk while riding & $9 \%$ \\
\hline
\end{tabular}

*When vehicles are present; * *When pedestrians are present; "Including bicycle paths (a few cases). 


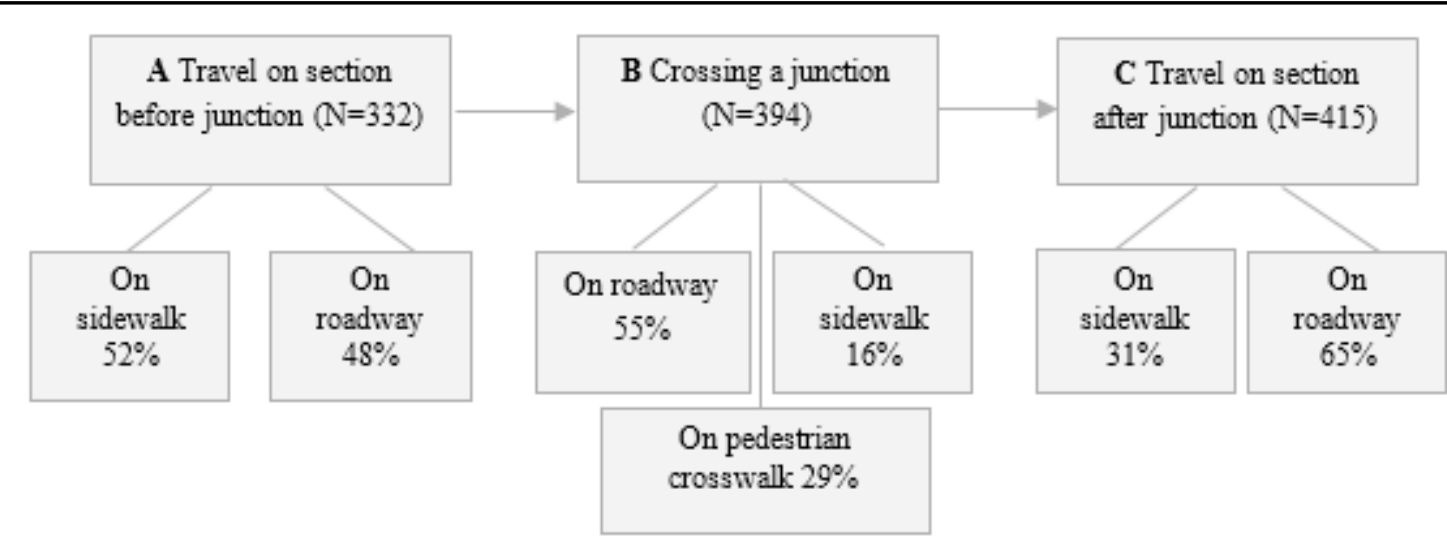

Figure 4. Place of riding of young e-cyclists at un-signalized junctions, near schools.

In consequent statistical analyses that examined the impacts of road and traffic conditions and/or riders characteristics on their behaviours, mostly insignificant results were obtained. Among significant results were that while travelling on a street section after the junction (step $\mathrm{C}$ ), a higher share of riders selects a roadway rather than a sidewalk on a divided road compared to an undivided two-lane road: $76 \%$ vs $66 \%$, respectively $(p=0.075)$. Simultaneously, we found that while riding on a roadway after the junction, more riders move slower than vehicles on a divided road compared to an undivided two-lane road: $77 \%$ vs $54 \%$, respectively $(\mathrm{p}=0.052)$. This implies that on a divided (dual-carriageway) road, more e-cyclists prefer the stay on the roadway after the junction, creating more disturbance to other vehicle traffic. Such a preference is particularly worrying as dual-carriageway roads are typically characterized by higher vehicle volumes and higher travel speeds than two-lane roads, which may increase the risk of e-cyclist injury.

In addition, in a statistical model fitted to the probability that a rider slows down before the junction while riding on the roadway (on step B), the impact of junction configuration was significant $(p<0.001)$ indicating that at a 4-legged junction more riders tend to slow down (compared to a 3-legged junction). Such a result is reasonable accounting for a higher complexity of movements at 4-legged junctions.

In general, at un-signalized junctions, a variety of e-cyclist behaviours that endanger the riders themselves and disturb other road users were observed. They move fast and frequently change the place of riding according to their instant convenience, being unpredictable for other road users and creating risky situations both on the roadway and on sidewalks. In the study sample for un-signalized junctions, in total, 4 conflicts were counted between e-cyclists and other road users (pedestrians and vehicles); they were classified as slight or medium, due to low speeds of both parties and time gaps of $2 \mathrm{sec}$ or more. In spite of the small number of conflicts observed in the study, the high frequencies of imprudent behaviours of young e-cyclists and their disobeying of traffic rules cannot be ignored due to a potential risk they impose on urban traffic.

\subsection{E-cyclist behaviours at signalized junctions, near schools and in city centers}

For an e-cyclist riding through a signalized intersection, two steps of movement were defined: crossing a junction (A) and travelling on a street section after the junction (B). It should be noted that at one intersection, an e-cyclist may be observed as riding through 1 to 6 crosswalks and that, in general, the e-cyclist presence at a signalized intersection is longer than at an un-signalized junction. A camera could follow an e-cyclist within a limited distance, thus, at signalized junctions the preference was given to observing crossing behaviours of e-cyclists and, if reachable, to their travelling on a street section after the junction, while the behaviours on a street section before the junction were not filmed. (As a result, we had two steps of movement at signalized junctions, while at un-signalized junctions there were three.) The samples of e-cyclists observed, in each step, in the near school areas and in city centers, were in the range of 181-431 (Figure 5). For the crossing step, riders' behaviours were summarized at all the crosswalks where they were observed. The summary statistics of e-cyclist behaviours at signalized junctions (Figure 5, Table 4) indicated that: 
- Both near schools and in city centers, most young e-cyclists prefer to cross the signalized junctions on crosswalks (67\%-82\%) and to ride on sidewalks after the junction (64\%-65\%), i.e. to use pedestrian facilities, in spite of the law prohibition.

- When the e-cyclists crossed a junction on the roadway, over $30 \%$ of them crossed on red and about $40 \%$ did not slow down before the junction. They exhibited such behaviours both near schools and in city centers, whereas in many cases (70\%) vehicle traffic was present at the junction. In addition, $5 \%-11 \%$ of e-cyclists went up the sidewalk while crossing the junction. The rate of red lights' violations by young e-cyclists in Israel was lower than that exposed by e-bikes in China (Yang et al, 2015). However, it is undoubtedly very high compared to motor vehicles.

- When the e-cyclists crossed a junction on pedestrian crosswalks, about $40 \%$ of them did not slow down before the crossing, 14\%-17\% crossed on red, about $80 \%$ moved faster than crossing pedestrians (when pedestrians were present) and $12 \%-17 \%$ continued the riding on the roadway. Almost all e-cyclists crossed while riding.

- When they rode on sidewalks after the junctions, in $30 \%-60 \%$ of cases pedestrians were present on the streets. In such cases, the e-cyclists typically (in about $80 \%$ of cases) moved faster than pedestrians.

- When e-cyclists rode on the roadway after the junction, they usually used the right lane, which is in line with the law. However, over $10 \%$ of riders used other lanes, thus violating the rules and disturbing vehicle traffic. The e-cyclists moved slower than vehicles in about $70 \%$ of cases where other vehicles were present on the road. Moreover, some riders $(5 \%-8 \%)$ changed their position on the roadway and others (3\%-5\%) went up to the sidewalk during the riding thus increasing the extent of disturbance for other road users.

Further statistical analyses did not find significant impacts of road conditions or rider characteristics on their tendency to cross on red. However, an impact of the number of crosswalks was ascertained in the statistical models fitted to some riders' behaviours on pedestrian crosswalks. We found that both near schools and in city centers, a higher number of crosswalks (that crossed by the rider) was associated with a decrease in the rider's intention to slow down before the crosswalk ( $p<0.001)$, and, also, with an increase in the rider's intention to change the place of riding to the roadway $(\mathrm{p}<0.05)$.

In addition, on the step of travelling on a street section after the junction (step B), the impact of road type on the selection of place of riding was found: a higher share of e-cyclists selected a sidewalk instead of roadway on a divided road compared to an undivided two-lane road: $71 \%$ vs $37 \%$ near schools $(p<0.001) ; 69 \%$ vs $50 \%$ in city centers $(p<0.05)$. Such a choice seems reasonable accounting for higher traffic volumes on divided roads but it contradicts the law.

In the sample collected at signalized junctions, in total, 16 conflicts between e-cyclists and other road users were observed, none of them severe. However, nine cases involved pedestrians pointing to the problem of using pedestrian facilities by e-bicycles. In general, young e-cyclist behaviours at signalized junctions demonstrated a wide range of traffic law violations and risky manoeuvres that endanger them and disturb other road users.

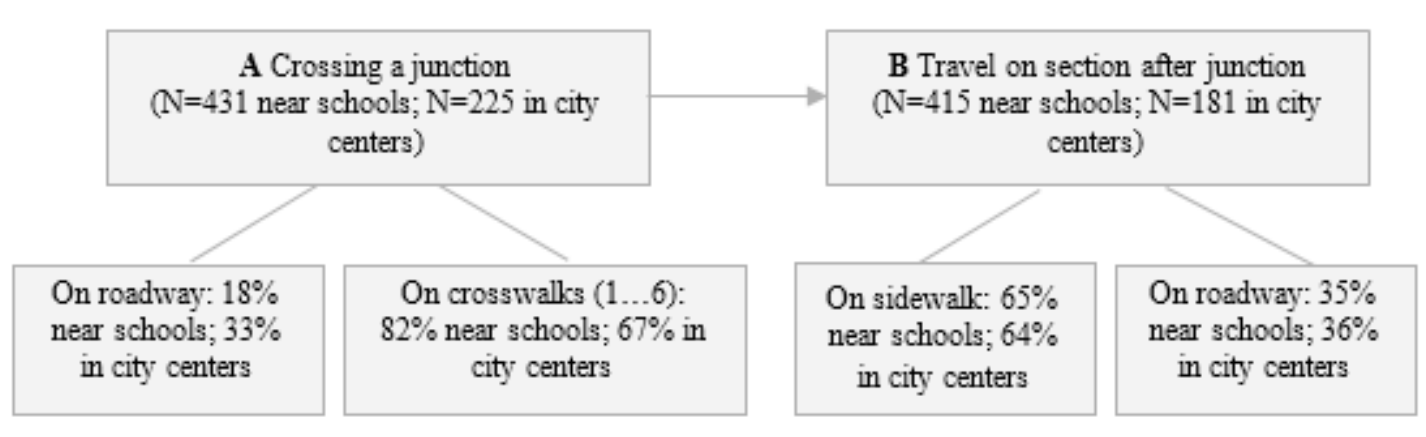

Figure 5. Place of riding of young e-cyclists at signalized junctions, in the near school areas and in city centers. 
Table 4. Young e-cyclists' behaviours and travel conditions at signalized junctions, near schools and in city centers.

a - Crossing a junction (step A)

\begin{tabular}{|c|c|c|c|c|}
\hline $\begin{array}{l}\text { Place of } \\
\text { riding }\end{array}$ & $\begin{array}{l}\text { Sample of e-cyclists observed: } \\
\text { (1) near schools, (2) in city centers }\end{array}$ & Rider's behaviours and travel conditions & $\begin{array}{l}\text { Frequency: } \\
\text { near schools }\end{array}$ & $\begin{array}{l}\text { Frequency: in } \\
\text { city centers }\end{array}$ \\
\hline \multirow[t]{5}{*}{ On roadway } & \multirow[t]{5}{*}{ (1) $77,(2) 74$} & Going straight (vs turning) & $49 \%$ & $72 \%$ \\
\hline & & Vehicle traffic was present at the junction & $70 \%$ & $70 \%$ \\
\hline & & Crossed on red & $31 \%$ & $32 \%$ \\
\hline & & Did not slow down before the junction & $44 \%$ & $38 \%$ \\
\hline & & Went up to the sidewalk while riding & $5 \%$ & $11 \%$ \\
\hline \multirow{7}{*}{$\begin{array}{l}\text { On } \\
\text { pedestrian } \\
\text { crosswalks }\end{array}$} & \multirow[t]{7}{*}{ (1) 354, , (2) $151^{\# \#}$} & $\begin{array}{l}\text { Crossed at signalized crosswalks } \\
\text { (vs un-signalized crosswalks) }\end{array}$ & $74 \%$ & $85 \%$ \\
\hline & & Crossed on red at signalized crosswalks & $14 \%$ & $17 \%$ \\
\hline & & Did not slow down before (any) crossing & $42 \%$ & $35 \%$ \\
\hline & & Crossed by riding & $99 \%$ & $100 \%$ \\
\hline & & Changed the place to roadway & $12 \%$ & $17 \%$ \\
\hline & & Pedestrians were present & $16 \%$ & $38 \%$ \\
\hline & & Moved faster than pedestrians** & $85 \%$ & $76 \%$ \\
\hline
\end{tabular}

b - Travel on a street section after the junction (step B)

\begin{tabular}{|c|c|c|c|c|}
\hline $\begin{array}{l}\text { Place of } \\
\text { riding }\end{array}$ & $\begin{array}{l}\text { Sample of e-cyclists observed: (1) } \\
\text { near schools, (2) in city centers }\end{array}$ & Rider's behaviours and travel conditions & $\begin{array}{l}\text { Frequency: } \\
\text { near schools }\end{array}$ & $\begin{array}{l}\text { Frequency: in } \\
\text { city centers }\end{array}$ \\
\hline Both & (1) 415, , (2) 181 & $\begin{array}{l}\text { Undivided two-lane road (vs a divided } \\
\text { road) }\end{array}$ & $20 \%$ & $28 \%$ \\
\hline \multirow[t]{3}{*}{ On sidewalk } & \multirow[t]{3}{*}{ (1) $268,(2) 115$} & Passed near pedestrians & $31 \%$ & $60 \%$ \\
\hline & & Moved faster than pedestrians** & $87 \%$ & $90 \%$ \\
\hline & & Went down to the road while riding & $1 \%$ & $1 \%$ \\
\hline \multirow[t]{5}{*}{ On roadway" } & \multirow[t]{5}{*}{ (1) $147,(2) 66$} & Rode on the right lane (vs others) & $84 \%$ & $88 \%$ \\
\hline & & Vehicle traffic was present on the road & $37 \%$ & $44 \%$ \\
\hline & & Moved slower than vehicles* & $75 \%$ & $69 \%$ \\
\hline & & Changed the position on the roadway & $8 \%$ & $5 \%$ \\
\hline & & Went up to the sidewalk while riding & $3 \%$ & $5 \%$ \\
\hline
\end{tabular}

*When vehicles are present; * ${ }^{*}$ When pedestrians are present; ${ }^{*}$ Including bicycle paths (a few cases). ${ }^{\#}$ Accounting for multiple crosswalks: (1) 851, (2) 325.

\section{SUMMARY AND CONCLUSIONS}

Being aware of a substantial increase in the use of e-bicycles by youngsters in Israeli towns, media reports on their seemingly dangerous behaviours and an increase in road traffic injury, an observational survey of young e-cyclists was undertaken in this study. The survey intended to explore the young e-cyclist behaviours at typical urban settings, to characterize their behavior patterns and interactions with other road users and, consequently, to consider measures needed for their safer integration in the urban environment. The survey focused on young e-cyclists' behaviours during their trips to and from school and in leisure hours, at a range of traffic settings, situated both near the high-schools and in city centers. 
The survey results indicated that, at all types of sites, most young e-cyclists were males, older than 16 and not wearing a helmet. In all the sites together, only $8 \%$ of riders wore a helmet. The shares of riders that carried a passenger was $10 \%$ and higher near the high schools - on street sections, signalized and un-signalized junctions and roundabouts, and also at signalized junctions in city centers. Therefore, the findings pointed out typical violations of traffic law in Israel by young e-cyclists, such as: not wearing a helmet (that is obligatory for cyclists below the age of 18), by the majority of young e-cyclists, and violations of the age restriction on the use of e-bicycles (should be over 16) and the prohibition on carrying a passenger - by a small share of riders (over $10 \%$, on average).

In addition, high shares of e-bicycles rode on sidewalks and crossed at crosswalks, violating the traffic law that prohibits using pedestrian facilities for riding. At signalized junctions, substantial shares of riders crossed on red lights, both on roadway and on crosswalks, thus violating the law and increasing accident risk. At various urban settings - signalized and un-signalized junctions and street sections, young e-cyclists demonstrated a wide range of traffic law violations and risky manoeuvres that endanger the riders and disturb other road users. Many of them do not slow down before a crosswalk or a junction; they may change the place of riding between the sidewalk and the roadway and inside the sidewalk or the roadway, according to their instant convenience. Young e-cyclists are faster than pedestrians and endanger them on sidewalks, but also slower than vehicles, disturb the vehicle traffic and endanger themselves while riding on the road. The high frequencies of imprudent behaviours of young e-cyclists and their apparent disobeying of traffic rules are obvious and need to be changed due to the risk they impose on all urban road users.

According to Traffic regulations (2016), standard e-bicycles may use regular bicycle infrastructure when available. Hence, for a safe integration of e-bicycles in the urban environment, two conditions are needed:

- Separating the sidewalks, bicycle paths and roadways, particularly on collector roads with higher vehicle traffic and pedestrian activities, by applying engineering solutions outlined in the urban streets' design guidelines (Guidelines, 2009);
- Ensuring enforcement of traffic regulations concerning e-bicycles, with a particular focus on the definition of standard e-bicycles (limiting the engine power and speeds) and a prohibition to all types of bicycles to use pedestrian facilities for riding.

In Israel, the construction of bicycle-related infrastructure in urban areas is still in its initial stage, where bicycle lanes and paths are not common yet in most Israeli towns. Frequently, bicycle paths stop at junctions, without an arrangement for bicycle crossings. As a result, many cyclists cross the road at pedestrian crosswalks, by riding, and, hence, violate the traffic law. The situation is even worse with teen e-cyclists, which, under the absence of bicycle paths, should ride on the road, in mixed traffic, thus endangering themselves. The alternative of riding on sidewalks that is selected by many young e-cyclists might be safer for them but creates a danger for pedestrians.

The literature does not suggest a separate "strip" for e-bicycles in the urban space. Thus, to promote a safe use of e-bicycles in Israeli cities, the main focus should be on a wider application of common bicycle infrastructure, in accordance with the design guidelines. Better separation between the sidewalks, roadways and bicycle paths, both on street sections and at junctions, will reduce the problem of speed differences and conflicts in the interaction between various road users. Moreover, in recently published guidelines abroad (e.g. MassDOT, 2015) there are examples of design solutions that enable a safer separation of bicycle facilities at various types of urban settings. Such solutions can be considered for adoption in Israeli practice, with potential safety benefits for both e-cyclists and conventional cyclists. The issue of connectivity in providing a cycling network, particularly in the vicinity of high schools, can be promoted in cooperation between the local authorities and school management.

In addition, in light of the high rates of traffic law violations observed in the field, road safety education and training of teen e-cyclists supported by stronger police enforcement are required in Israel. In particular, the involvement of high school administration is necessary to apply the regulation on age limit in using e-bicycles, for example, by restricting the use of school bicycle parking. The use of helmets by e-riders can be promoted by publicity campaigns and mutual efforts of school administration and parents. Lessons on e-bicycle traffic regulations and training of safe cy- 
cling can be conducted at high schools by the police officers and volunteers. Examples of such initiatives were recently reported by the Traffic department of the Israeli police. Finally, enforcement activities with regard to the e-cyclists' age restriction, helmet use and the place of bicycle riding can be undertaken by local authorities in cooperation with the police.

Acknowledgements: This research was supported by the Ministry of Science, Technology and Space, Israel.

\section{REFERENCES}

Boele-Vos, M.J., Commandeur, J.J.F., Twisk, D.A.M. (2017). Effect of physical effort on mental workload of cyclists in real traffic in relation to age and use of pedelecs. Accident Analysis and Prevention, 105, 84-94.

Cherry, C. and Cervero, R. (2007). Use Characteristics and mode choice behavior of electric bike users in China. Transport Policy, 14(3), 247-257.

Dozza, M., Werneke, J., Mackenzie, M. (2013). E-BikeSAFE: A naturalistic cycling study to understand how electrical bicycles change cycling behaviour and influence safety. In Proceeding of International Cycling Safety Conference 2013, 20-21November 2013, Helmond, The Netherlands.

Dozza, M., Piccinini, G.F.B., Werneke, J. (2016). Using naturalistic data to assess e-cyclist behavior. Transportation Research Part F, 41, 217-226.

Du, W., Yang, J., Powis, B., Zheng, X., Ozanne-Smith, J., Bilston, L., Wu, M. (2013). Understanding on-road practices of electric bike riders: An observational study in a developed city of China. Accident Analysis and Prevention, 59, 319-326.

European Norms EN 15194 (2009). Cycles. Electrically power assisted cycles. EPAC bicycles.

Ewing, R., and Dumbaugh, E. (2009). The built environment and traffic safety: A review of empirical evidence. Journal of Planning Literature, 23(4), 347-367.

Fishman, E. and Cherry, C. (2016). E-bikes in the mainstream: Reviewing a Decade of Research. Transport Reviews, 36:1, 72-91.

Fleiss, J.L., Levin, B., Cho Paik, M. (2004). Statistical Methods for Rates and Proportions. 3rd Edition. John Wiley and Sons.

Free Import Order 871190302 (2011). Electric bicycles and scooters. Israel. Retrieved from http://www.sustainability.org. il/home/bike-news/regulation-electric-bicycles-Israel-2011

Fyhri, A. and Fearnley, N. (2015). Effects of e-bikes on bicycle use and mode share. Transportation Research Part D: Transport and Environment, 36, 45-52.

Gertner Institute (2014). Electric bicycles and scooters injury. Retrieved from http://www.gertnerinst.org.il/health_policy/ trauma/trauma_research/706.htm
Gertner Institute (2015). A position paper of the National Center for Trauma and Emergency Medicine Research on the subject of electric bicycles and scooters injury. Retrieved from http://www. gertnerinst.org.il/health_policy/trauma/trauma_publications/ trauma_publications_reports/

Gitelman, V., Carmel, R., Pesahov, F., Chen, S. (2017). Changes in road-user behaviors following the installation of raised pedestrian crosswalks combined with preceding speed humps, on urban arterials. Transport Research Part F, 46, 356-372.

Guidelines (2009). Urban streets' design guidelines. Ministry of Transport and Ministry of Construction and Housing, State of Israel. Retrieved from http://he.mot.gov.il/index. php?option=com_content\&id=541:tt-trbo-a\&Itemid=124

Hu, F., Lv, D., Zhu, J., Fang, J. (2014). Related risk factors for injury severity of e-bike and bicycle crashes in Hefei. Traffic Injury Prevention, 15:3, 319-323.

Hurst, D. and Gartner, J. (2013). Electric bicycles global market opportunities, barriers, technology issues, and demand forecasts for e-bicycles, pedal-assist bicycles and e-bicycle batteries and motors. Navigant Consulting, Inc., USA. Retrieved from http:// www.navigantresearch.com

Johnson, M., Rose, G. (2013). Electric bikes-cycling in the new world city: an investigation of Australian electric bicycle owners and the decision making process for purchase. In Proceedings of Australasian Transport Research Forum 2013, 2-4 October 2013, Brisbane, Australia. Retrieved from http://www.patrec. org/atrf.aspx

Langford, B.C., Chen, J., Cherry, C.R. (2015). Risky riding: Naturalistic methods comparing safety behavior from conventional bicycle riders and electric bike riders. Accident Analysis and Prevention, 82, 220-226.

MacArthur, J. and Kobel, N. (2014). Regulations of E-bikes in North America, a policy review. Report NITC-RR-564. Portland State University, for National Institute for Transportation and Communities.

MacArthur, J., Dill, J., Person, M. (2014). E-Bikes in the North America: Results from an online survey. In Proceedings of the 93 ${ }^{\text {rd }}$ Annual Meeting of the Transportation Research Board, January 12-16, 2014.

MassDOT (2015). Separated bike lane planning \& design guide. Massachusetts Department of Transportation. Retrieved from https://www.massdot.state.ma.us/highway/DoingBusinessWithUs/ManualsPublicationsForms/SeparatedBikeLanePlanningDesignGuide.aspx

Morgenstein, D. (2016). Electric bikes - a transportation disaster or an urban solution? Status - Journal of Managerial and Strategic Thinking, 13 June 2016. Retrieved from www.status. $\underline{\text { co.il }}$

Petzoldt, T., Schleinitz, K., Heilmann, S., Gehlert, T. (2017). Traffic conflicts and their contextual factors when riding conventional vs. electric bicycles. Transportation Research Part F, $46,477-490$.

Popovich, N., Gordon, E., Shao, Z., Xing, Y., Wang, Y., Handy, S. (2014). Experiences of electric bicycle users in the Sacramento, California area. Travel Behaviour and Society, 1, 37-44. 
Rose, G. (2012). E-bikes and urban transportation: emerging issues and unresolved questions. Transportation, 39, 81-96.

Scaramuzza, G., Uhr, A., Neimann, S. (2015). E-Bikes im Strassenverkehr - Sicherheitsanalyse. Bfu-report nr. 72. Beratungsstelle fur Unfallverhutung.

Schepers, J. P., Fishman, E., den Hertog, P., Klein Wolt, K., Schwab, A. L. (2014), The safety of electrically assisted bicycles compared to classic bicycles. Accident Analysis and Prevention, 73, 174-180.

Schleinitz, K., Petzoldt, T, Franke-Bartholdt, L., Krems, J., Gehlert, T. (2017). The German Naturalistic Cycling Study - Comparing cycling speed of riders of different e-bikes and conventional bicycles. Safety Science, 92, 290-297.

Traffic Regulations (2016). Retrieved from https://www.nevo. co.il.law_htm/Law01

Van der Horst, A.R.A., de Goede, M., de Hair-Buijssen, S., Methorst, R. (2014). Traffic conflicts on bicycle paths: A systematic observation of behaviour from video. Accident Analysis and Prevention, 62, 358-368.

Yang, X., Huan, M., Abdel-Aty, M., Pemg, Y., Gao, Z. (2015). A hazard-based duration model for analyzing crossing behavior of cyclists and electric bike riders at signalized intersections. Accident Analysis and Prevention, 74, 33-41. 